\title{
Parkour as Health Promotion in Schools: A Qualitative Study on Health Identity
}

\author{
Dan Grabowski ${ }^{1, *} \&$ Signe Dalsgaard Thomsen ${ }^{1}$ \\ ${ }^{1}$ Health Promotion Research, Steno Diabetes Center, 2820 Gentofte, Denmark \\ "Correspondence: Health Promotion Research, Steno Diabetes Center, Niels Steensens Vej 8, 2820 Gentofte, \\ Denmark. E-mail: dgbo@steno.dk
}

Received: April 16, 2015

Accepted: May 8, 2015 Online Published: May 12, 2015

doi:10.5430/wje.v5n3p37

URL: http://dx.doi.org/10.5430/wje.v5n3p37

\begin{abstract}
In the present paper, we highlight the potential role of parkour in school-based health promotion. In a school setting, it is often difficult to promote health and healthy behaviour in ways that make sense and appeal to pupils. Research suggests that initiatives incorporating a focus on identity and on presenting health in new and different ways are more likely to succeed in generating engagement, participation and involvement and thereby to affect learning outcomes and behaviour change. In the present paper, we explore and discuss parkour as just such a new and different approach. We do this using an empirically and theoretically tested concept of health identity as our main theoretical and analytical component. We present our findings in three main themes: 1) Changed self-images provide opportunities for social inclusion, 2) New observations of others force pupils to reconsider roles and hierarchies and 3) Togetherness and non-competitiveness generate a sense of belonging. The paper provides teachers and school health practitioners with important knowledge about why they may wish to incorporate parkour into school health promotion and equally important knowledge about how a focus on health identity is essential if they are to ensure conditions that facilitate significant health-promoting effects for all pupils - not just for those who are already healthy.
\end{abstract}

Keywords: parkour; health promotion; identity; school; participation

\section{Introduction}

Health promotion in schools often fails to engage and involve pupils in ways that affect learning and behaviour (Grabowski, 2013a, 2013b; Grabowski \& Rasmussen 2014b; Peters et al., 2009; Wistoft, 2010). Research in the area suggests that initiatives incorporating a focus on identity are more likely to succeed in generating engagement, participation and involvement and thereby to affect learning outcomes and behaviour change (Grabowski \& Rasmussen, 2014b; Harrell-Levy \& Kerpelman, 2010; Taylor, 1991). There is also evidence to suggest that such effects are most likely to occur when health and healthy behaviour are presented in new and different ways (Grabowski \& Rasmussen, 2014a). In the present paper, we discuss parkour as just such a new and different approach.

Parkour is an emerging lifestyle sport and physical discipline, the aim of which is to move as smoothly, quickly and effectively as possible from one location to another. This is done by overcoming obstacles, both physical and emotional, and doing so using only the body (e.g., Ameel \& Tani, 2012; Angel, 2011; Gilchrist \& Wheaton, 2011; Saville, 2008; Wheaton, 2004). Parkour is an activity that involves learning how to overcome one's fears and limitations by mastering both the body and the mind (Angel, 2011). It has its own set of values that in many ways differ from both traditional and other lifestyle sports (Gilchrist \& Wheaton, 2011). Practitioners of parkour do not compete against each other; instead parkour is about challenging oneself and one's level of skill both physically and mentally (Gilchrist \& Wheaton, 2011; Angel, 2011). Effort and attitude are rewarded rather than ability. The parkour community is characterized as being non-hierarchical, inclusive and responsible. The inclusive aspect of parkour is visible in the way beginners and outsiders are supported and embraced in the parkour community (Gilchrist \& Wheaton, 2011; Clegg \& Butryn, 2012). Parkour is less rule-bound than most sports. Although there are specific techniques, parkour does not have a distinct set of rules or objectives that need to be followed (Gilchrist \& Wheaton, 2011). Angel (2011) describes parkour as a discipline that affects identity and perception of the self by being an 
explicit mode of self-expression. The present paper will delve more deeply into the identity aspect, with a view to analysing the potential learning and behavioural outcomes of parkour as a school-based health promotion initiative.

Parkour has received relatively little attention as a research topic (Brunner, 2011), but is beginning to attract academic interest (Ameel \& Tani, 2012). Atkinson (2009) interprets parkour as a new version of flâneurism, because parkour practitioners use the urban environment in innovative and playful ways that differ from the accepted norms and rhythms of cities. Bavinton (2007) examines one of parkour's key values -i.e., turning obstacles into opportunities - and concludes that parkour practitioners reinterpret constraints instead of removing them, thereby using spaces in personal and creative ways. One of Bavinton's conclusions is that parkour practitioners' interactions with obstacles promote their sense of agency as individuals. Kidder (2013) focuses on fear in relation to parkour and states that the sport involves an ever-present risk of physical injury. Kidder describes parkour as a form of urban adventurism, which revolves around what Kidder calls 'rites of risk' (i.e., actions that put one's corporeal self on the line) and 'rituals of safety' (i.e., following a set of progressive steps). Ameel and Tani (2012) suggest that parkour practitioners form unique and embodied relationships with their daily surroundings, because they attach emotions to the surroundings. Parkour practitioners achieve a sense of belonging to their immediate environment, because they ascribe new meanings to their everyday spaces. Gilchrist and Wheaton have examined the use of parkour as a way of reducing antisocial behaviour while promoting social inclusion and increasing physical activity. Their research shows that parkour can promote physical health, well-being and community engagement among groups that normally do not participate in traditional sports and physical activity (2011).

There tends to be a sense of dissatisfaction among researchers working with identity-related issues. Bendle describes how the increased focus on identity renders use of the concept "inconsistent, under-theorized and incapable of bearing the analytical load required" (Bendle, 2002: 1). Hall focuses on a paradoxical development involving both a discursive explosion in use of the concept of identity and a growing criticism, resulting in a kind of conceptual deconstruction (Hall, 2001). This conceptual confusion and negative critique serve both as a reason for conducting contemporary identity research and as a barrier to such research. Coté and Schwartz compare psychological and sociological approaches to identity. They describe how psychologists and sociologists have created a span of possible meanings, ranging from intrapsychic viewpoints to macro-social viewpoints. They argue that although these approaches use different terminologies, they have in fact identified similar processes, thus rendering unnecessary the often strict division between the sociological and the psychological (Coté \& Schwartz, 2002).

Identity is rarely used as an active concept in health promotion research. The present paper uses an empirically and theoretically tested concept of health identity that has evolved over the course of recent studies (Grabowski, 2013a \& 2013b; Grabowski \& Rasmussen, 2014b). The concept has been developed for the express purpose of combining health promotion research and identity research and is defined as: "Children's and adolescents' observations and expectations concerning their own health, their knowledge about health and in what ways their health is related and comparable to the health of others" (Grabowski \& Rasmussen, 2014b). This definition describes how health identity is developed on the basis of individually perceived yet socially constructed expectational structures and social imaginaries that impact on health values, health beliefs and health choices, meaning that health identity is neither strictly sociological nor psychological in nature. Health identity functions as a way of orientating and navigating in the complexities of health education, health information and possible health behaviours. The concept also focuses on how identity aspects outside the area of health affect the way in which we understand and interpret ourselves as healthy or unhealthy.

Little is known about parkour as a health promotion initiative, and even less is known about the potential roles health identities may play when introducing parkour into a school environment. The main objective of the present article is therefore: To analyse and discuss whether and how an analytical framework focusing on health identity can be used to observe and elaborate upon the potential of using parkour as a form of school-based health promotion.

\section{Methods}

\subsection{The Context of the Study}

The study explores three empirical settings. Two of these $(2 \& 3$ below) are in a school context and the third (1 below) is in a non-school context included to gain knowledge about other potential aspects of parkour:

1) Organized and regular parkour training: A private organization offering organized training in parkour. The training is divided into different classes depending on age. The instructors are young people who have practiced 
parkour for several years and who all are certified ADAPT instructors(Note 1).

2) Parkour workshops: In this setting, school classes participate in parkour workshops. The instructors are from the same organization as above. The workshops are primarily aimed at children and adolescents who lack detailed knowledge about parkour.

3) Parkour in primary school physical education: Here, children are taught parkour by their teachers, who have previously taken a parkour course for schoolteachers.

\subsection{Data Collection}

Data collection differed in the three settings. Nevertheless, the practicalities are similar enough that the process can be described as a whole. In each of the empirical settings, children/adolescents were asked to volunteer for interviews. From the volunteers, three to four children/adolescents were chosen to participate in a group interview.

We have conducted:

- 10 semi-structured group interviews with children/adolescents aged 6 to 18 years, who attend organized parkour training regularly.

- 7 semi-structured group interviews with adolescents aged 13 to 14 years, who participated in parkour workshops.

- 8 semi-structured group interviews with children aged 9 to 10 years, who received parkour training in school from their physical education teacher.

These interviews lasted as long as the children and adolescents had something to say and could maintain a reasonable level of concentration. The main themes in the interview guides were:

- What do you think about parkour?

-What did you think about the parkour lessons/workshop/practice?

- How were the parkour lessons/workshop/practice organized?

- What did you think of the parkour instructor/teacher?

- What did you learn from the parkour lessons/workshop/practice?

- Are you physically active in your everyday life?

We conducted four semi-structured interviews with teachers who accompanied the children to workshops and two interviews with teachers who introduced parkour in physical education, after having attended the instructor course.

The interviews lasted as long as the teachers had something to say. The main themes in the interview guides were:

- What do you think about parkour in general?

- How were the parkour lessons/workshop organized?

-What did the pupils learn from the parkour lessons/workshop?

- What was it like to teach parkour? What did you think of the instructors?

- How does parkour fit into everyday health promotion in school?

- Are these pupils physically active/healthy?

\subsection{Data Analysis}

The interviews with children/adolescents and teachers are given equal priority in the analysis. All interviews were transcribed and iteratively analysed and categorized using Rasmussen's guidelines for content analysis, which, because they contain a combination of hermeneutics and constructivism, manage to be at once empirically true and complexity oriented (Rasmussen, 2004). Radical hermeneutics focuses on always maintaining a balance between theory, method and data by acknowledging this as an interconnected process that requires a continual focus on how all of the elements influence each other. The use of radical hermeneutics also entails constant alternation between analysis and interpretation.

Radical hermeneutics involves three steps of data analysis. In the first step, the data are read with a view to observing how specifically selected guiding differences or interpreter's differences are observed in the data. This observation in itself constitutes an interpretation rather than a description. Its purpose is to reduce the complexity of the data. Elements within the scope of the differences selected by the interpreter are extracted from the data. The second step involves making these elements the subject of interpretation as an observation of the difference(s) employed. The 
third step involves an interpretation of the sum of these differences (Rasmussen 2004).

In this analysis, the analytical process was developed in the following steps: The first step focused on searching for elements related to health identity in the data. This first selective interpretation reduces the complexity of the empirical data significantly. The second step is an analysis and interpretation of this selected empirical data. This step disclosed the three health-identity-related themes that are presented in the findings section. The third step is the analysis and interpretation of these three themes. Carrying out the analysis and interpretation in these steps makes it easy to keep track of the choices and distinctions that are made throughout the process. This makes the process transparent and ensures a high level of methodological reflexivity.

\section{Findings}

\subsection{Changed Self-Images Provide Opportunities for Social Inclusion}

Parkour challenges the ways in which children and adolescents see themselves. Across the three settings, it is evident that it offers new opportunities for self-observation and thereby for the construction and re-shaping of health identities: "I quickly began to challenge myself because I usually know what I can do and what I can't do. But then I discovered I could do some things that I didn't think I could do as well as some things I couldn't do that I actually thought I could do" (Girl, 10 years, Setting 3). Doing more traditional sports would not produce this potential for change and for relating to health and physical exercise in new ways. Discovering new abilities as well as having to write off existing abilities is a common experience among the children/adolescents engaging in parkour for the first time: "I didn't know I could carry my own weight using my arm" (Boy, 11 years, Setting 3). Apart from providing new possibilities for self-observation, these new ways of seeing themselves also provide opportunities for social inclusion, meaning that the children/adolescents now see themselves as people who can do sporty and thereby healthy things.

For the children/adolescents practising regular parkour training, the opportunities for new self-observations are even more evident and go beyond discovering new physical abilities: "Well, I'm still not exactly skinny. I'm still kinda big. But now I guess I'm more the chubby guy rather than the really fat guy" (Boy, 12 years, Setting 1). This boy is not only observing his own physical appearance in a new way. He is also implicitly observing how his classmates observe him and how he feels he fits into the health hierarchy at school.

The fact that parkour represents an entirely different lifestyle, with its own set of accepted behaviours and with a new way of relating to movement, is also evident among the children/adolescents who practise the sport regularly: "Before parkour I saw myself as someone who didn't really move at all. I just basically moved as little as possible. Now I've started to go for walks just for the sake of walking. I would never have done that before" (Boy, 12 years, Setting 1). And even more telling: "I couldn't do anything before. I went from sitting in front of the TV eating candy all day long to doing all kinds of sports - because of parkour" (Boy, 11 years, Setting 1). Naturally, major behavioural changes such as these will not materialize instantly after parkour is briefly presented to children in school, but the above quotes, and several more like them, show us that the sport has the potential to promote significant identity and lifestyle changes and that even brief exposure to it might result in minor changes - changes that could be of significance when making future choices regarding exercise or health in general.

\subsection{New Observations of Others Force Pupils to Reconsider Roles and Hierarchies}

The collective construction of meaning and thereby of identities is significant in a new activity like parkour. Even seemingly firm classifications and imaginaries are challenged: "We've got a guy in our class who is really quiet and usually just walks around on his own. Today we got a completely different impression of him. He was totally caught up in it. That was really cool to see" (Girl, 14 years, Setting 2).

In many school classes, there are firm expectational structures regarding physical exercise and gender. These expectations are also challenged: "The girls really impressed me. We have some girls in our class who are really quiet. But they joined in and did it all. So it wasn't just for the boys. I thought we were really good at it" (Girl, 15 years, Setting 2). This was also the case among the children who were taught parkour by their teacher: "There are some boys who normally wouldn't do this kind of thing. They were surprisingly good at it" (Girl, 9 years, Setting 3).

These possible new constructions of expectational structures, meanings and identities regarding both individuals and groups mean that the children/adolescents are forced to reconsider roles and hierarchies related to healthy behaviour. Inherent in such a process of reconsidering and re-shaping identities is the potential for identifying with new things, for social inclusion and for developing a sense of belonging to the various groupings within the school class and to the entire school - including the possibility of identifying with health education and health promotion. 
It is not only among the schoolchildren that identities and roles are challenged. The teachers play a significant role in the constant and mutual re-construction of identities: "They know each other's abilities in all sorts of sports. When they play football they know exactly who's the best and who's the second best and so on. Doing something like this really mixes things up and they really surprised each other - and me" (Teacher, Setting 2). The teachers all noticed that the normal roles and identities were being challenged, and they all saw this as something they really should do more often.

\subsection{Togetherness and Non-Competitiveness Generate a Sense of Belonging}

A strong feature of doing parkour is the sense of togetherness and camaraderie it communicates. In the organized parkour training, this stands out as a form of non-competitiveness that welcomes new participants: "It's not a matter of trying to be no.1. It's not a competition like that. It's a team effort and we do it together. We end and start together. Normally I'm actually quite competitive but not when I do parkour and that feels great" (Boy, 13 years, Setting 1). This non-competitiveness is important in attracting individuals who normally do not participate in sports and who therefore see themselves as non-sporty. Promoting a sense of belonging to health-related areas is a significant step en route to identifying with health information and healthy behaviour, and it therefore plays a significant role in the development and shaping of health identities.

Another aspect of this team feeling is the fact that helping other team members to improve is a common goal: "I think it's really cool that if someone is really skilled they always come over and help those of us who aren't so great yet" (Boy, 15 years, Setting 1). This openness and sense of equality also enable collective identifications within a health-related domain. Moreover, this element of health makes parkour significantly different from many of the other sub-cultural contexts children/adolescents encounter and identify with.

In the school context, this flat hierarchy and inherent togetherness encourage pupils to observe their (parkour participating) teachers in a new light as well: "They [their teachers] relaxed a bit more and got out of the teacher role and did the things together with us. They showed us that they have a fun side and could enjoy themselves with us" (Girl, 14 years, Setting 2). Challenging the established relationship between teachers and pupils enables changes in the way teachers are normally viewed (as experts), and this affects how pupils identify with teachers - and potentially the messages teachers communicate.

\section{Discussion}

The present study shows that parkour has real potential in school health promotion, especially in terms of reaching pupils who are normally uninterested in exercise and health in general. Looking at the potential of parkour in schools through a health identity lens would seem to be especially relevant, as parkour has many of the characteristics of a sub-culture, including being a strong foundation for group identification and identity construction - both because all practitioners are individually unique and because they are collectively accepted.

The main finding of the present study, across the three empirical settings, is that parkour offers children/adolescents a context that can turn established hierarchies and roles upside-down and thereby pave the way for fresh self-observations and the re-shaping of health identities. Identifying with health-related behaviour is important if one is to relate to future health promotion and health communication.

The strengths of our study include the empirical design, which enabled us to study parkour in three unique settings. It is also a strength that the interview guides were effective in encouraging the children/adolescents to talk about and reflect on their experiences with parkour on a level that provided us with ample data to analyse and discuss on an informed level.

The limitations of the study include our dependence on interviews with the relatively few school classes available for empirical Setting 2 and Setting 3. This meant that we could not structure the data collection freely.

The research results provide teachers with important general knowledge, namely that health promotion approaches should focus on health identity mechanisms in order to create conditions that generate a significant health education effect for all pupils - not only for those who are already healthy. The study also provides concrete knowledge for physical education teachers trying to reach pupils who are not naturally attracted to regular school sports.

This research has opened several potentially interesting perspectives for further investigations into the role of parkour in school health promotion and health education. The connection between parkour, health identity and healthy behaviour needs to be studied more closely and will be relevant to look at using health pedagogical theories on action competence (Jensen, 1997). Examining the relational contexts created by parkour could be closely related 
to studies of social capital and health (Ferlander, 2007), and taking a closer look at parkour's potential role in addressing issues of health inequalities (Diderichsen et al., 2012) could also be relevant in elaborating on the benefits of introducing parkour in health promotion and health education in school.

\section{References}

Ameel, L., \& Tani, S. (2012). Everyday aesthetics in action: Parkour eyes and the beauty of concrete walls. Emotion, Space and Society, 5, 164-173. http://dx.doi.org/10.1016/j.emospa.2011.09.003

Angel, J. (2011). Ciné Parkour - A cinematic and theoretical contribution to the understanding of the practice of parkour. Julie. Angel: London.

Atkinson, M. (2009). Parkour, Anarcho-Environmentalism, and poiesis. Journal of Sport \& Social Issues, 33(2), 169-194. http://dx.doi.org/10.1177/0193723509332582

Bavinton, N. (2007). From obstacle to opportunity: Parkour, leisure, and the reinterpretation of constraints. Annals of Leisure Research, 10(3-4), 391-412. http://dx.doi.org/10.1080/11745398.2007.9686773

Bendle, M.F. (2002). The crisis of 'identity' in high modernity. British Journal of Sociology, 53(1), 1-18. http://dx.doi.org/10.1080/00071310120109302

Brunner, C. (2011). Nice-looking obstacles: Parkour as urban practice of deterritorialization. AI \& Society, 26(2), 143-152. http://dx.doi.org/10.1007/s00146-010-0294-2

Clegg, J. L., \& Butryn, T. M. (2012). An existential phenomenological examination of parkour and free running. Qualitative Research in Sport, Exercise and Health, 4(3), 320-340. http://dx.doi.org/10.1080/2159676X.2012.693527

Coté, J.E., \& Schwartz, S.J. (2002). Comparing psychological and sociological approaches to identity: Identity status, identity capital, and the individualization process. Journal of Adolescence, 25, 571-586. http://dx.doi.org/10.1006/jado.2002.0511

Diderichsen F., Andersen I., \& Manuel C. (2012). Health Inequality: Determinants and Policies. Scandinavian Journal of Public Health, 40(8), 12-105. http://dx.doi.org/10.1177/1403494812457734

Ferlander, S. (2007). The Importance of Different Forms of Social Capital for Health. Acta Sociologica, 50, 115-128. http://dx.doi.org/10.1177/0001699307077654

Gilchrist, P., \& Wheaton, B. (2011). Lifestyle sport, public policy and youth engagement: examining the emergence of parkour. International Journal of Sport Policy and Politics, 3(1), 109-131. http://dx.doi.org/10.1080/19406940.2010.547866

Grabowski, D. (2013a). Identity, knowledge and participation: Health theatre for children. Health Education, 113(1), 64-79. http://dx.doi.org/10.1108/09654281311293646

Grabowski, D. (2013b). Health identity, participation and knowledge: A qualitative study of a computer game for health education among adolescents in Denmark. Health Education Journal, 72(6), 761-768. http://dx.doi.org/10.1177/0017896912469559

Grabowski, D., \& Rasmussen, K.K. (2014a). Authenticity in health education for adolescents: A qualitative study of four health courses. Health Education, 114(2), 86-100. http://dx.doi.org/10.1108/HE-06-2013-0020

Grabowski, D., \& Rasmussen, K.K. (2014b). Adolescents' health identities: A qualitative and theoretical study of health education courses. Social Science \& Medicine, 120, 67-75. http://dx.doi.org/10.1016/j.socscimed.2014.09.011

Hall, S. (2001). Who Needs Identity? In du Gay, P., Evans, J., \& Redman, P. (Eds.), Identity: A Reader. Sage Publications Inc., London, 15-33.

Harrell-Levy, M.K., \& Kerpelman (2010). Identity Process and Transformative Pedagogy: Teachers as Agents of Identity Formation. Identity, 10(2), 76-91. http://dx.doi.org/10.1080/15283481003711684

Jensen, B.B. (1997). A Case of two paradigms within health education. Health Education Research, 12(4), 419-428. http://dx.doi.org/10.1093/her/12.4.419

Kidder, J. L. (2013). Parkour: Adventure, Risk, and Safety in the Urban Environment. Qualitative Sociology, 36(3), 231-250. http://dx.doi.org/10.1007/s11133-013-9254-8 
Peters, L.W.H., Wiefferink, C.H., Hoekstra, F., Buijs, G.J., ten Dam, G.T.M., \& Paulussen, T.G.W.M. (2009). A review of similarities between domain-specific determinants of four health behaviors among adolescents. Health Education Research, 24(2), 198-232. http://dx.doi.org/10.1093/her/cyn013

Rasmussen, J. (2004). Textual interpretation and complexity: Radical hermeneutics. Nordisk Pedagogikk, 24(3), 177-194.

Saville, S. J. (2008). Playing with fear: parkour and the mobility of emotion. Social \& Cultural Geography, 9(8), 892-914. http://dx.doi.org/10.1080/14649360802441440

Taylor, C. (1991). The Ethics of Authenticity. Harvard University Press: Cambridge.

Wheaton, B. (2004). Introduction: mapping the lifestyle sport-scape. In: Understanding lifestyle sports consumption, identity and difference, Wheaton, B. (red.). Routledge, London.

Wistoft, K. (2010). Health Strategies and reservoirs of knowledge among adolescents in Denmark. Global Health Promotion, 17(2), 16-24. http://dx.doi.org/10.1177/1757975910365233

\section{Note}

Note 1. The ADAPT certification is the international standard for parkour instructors; it ensures that the instructor teaching others about parkour will do so in a knowledgeable, professional, competent and safe manner. 